\title{
Synthesis and DFT Study of a Diphenylsilanone-Bridged Dimolybdenum Complex
}

\author{
M. Angeles Alvarez, M. Esther García, Daniel García-Vivó, ${ }^{*}$ Sonia Menéndez and Miguel A. Ruiz*
}

\begin{abstract}
Reaction of the 30-electron benzylidyne complex $\left[\mathrm{Mo}_{2} \mathrm{Cp}_{2}(\mu-\mathrm{CPh})(\mu-\mathrm{PCy})(\mu-\mathrm{CO})\right]$ with excess $\mathrm{Ph}_{2} \mathrm{SiH}_{2}$ under visibleUV irradiation yields the silylene-bridged complex $\left[\mathrm{Mo}_{2} \mathrm{Cp}_{2}(\mu-\right.$ $\left.\mathrm{CPh})\left(\mu-\mathrm{PCy}_{2}\right)\left(\mu-\mathrm{SiPh}_{2}\right)\right]$. This compound undergoes selective oxidation with $\mathrm{O}_{2}$ to give the unsaturated complex $\left[\mathrm{Mo}_{2} \mathrm{Cp}_{2}(\mu-\right.$ $\left.\mathrm{CPh})\left(\mu-\mathrm{PCy}_{2}\right)\left(\mu-\kappa^{1}: \kappa^{1}-\mathrm{OSiPh}_{2}\right)\right]$, which contains an unprecedented bridging diphenylsilanone ligand as confirmed by $\mathrm{X}$-ray diffraction analysis and DFT calculations. The bonding within the central $\mathrm{Mo}_{2} \mathrm{SiO}$ ring of this complex approaches the extreme description of a dimetallacyclosiloxane, according to the relevant solid-state bond lengths and theoretical calculations.
\end{abstract}

Access to stable silanones $\left(\mathrm{R}_{2} \mathrm{Si}=\mathrm{O}\right)$, the heavier congeners of ketones, has been one of the holy-grails in the chemistry of main-group elements since the pioneering work of Kipping and Lloyd at the beginning of the past century. ${ }^{[1]}$ However, unlike ketones, these molecules are exceedingly reactive and until very recently they could be only identified either in the gas phase or trapped in cryogenic matrixes. ${ }^{[2]}$ Under more conventional conditions they typically evolve very rapidly through oligomerization or polymerization to give stable polysiloxanes $\left(\mathrm{R}_{2} \mathrm{SiO}\right)_{n}$, one of the most important types of inorganic polymers. ${ }^{[3]}$ This extraordinary tendency to oligomerization follows from the weak and strongly polarized $\pi(\mathrm{Si}-\mathrm{O})$ bond in the monomeric form of these molecules (A in Figure 1$),{ }^{[4]}$ this rendering the head-to-tail polymerization as an essentially barrierless process. ${ }^{[5]}$ Nevertheless, numerous synthetic routes have been devised to generate these molecules and trap them in situ with suitable reagents, to give a plethora of siliconcontaining derivatives. ${ }^{[4,6]}$ More recently, some strategies have been designed to stabilize these molecules in its monomeric form. A particularly fruitful one was initially developed by Driess and co-workers, based on the coordination of strong Lewis bases (typically N-heterocyclic carbenes (NHC's) or substituted pyridines) to the silicon atom (B in Figure 1$),{ }^{[7]}$ which eventually prevents oligomerization. This strategy was used for the stabilization of other related molecules having $\mathrm{Si}=\mathrm{O}$ bonds; ${ }^{[8]}$ however, all these compounds bearing a tetrahedral fourcoordinate silicon center are likely better described as zwitterionic silanolates (B in Figure 1). Even more recently, the coordination to transition metal centers has appeared as an

[*] Dr. M.A. Alvarez, Prof. Dr. M. E. García, Dr. D. García-Vivó, Dr. S. Menéndez, Prof. Dr. M. A. Ruiz,

Departamento de Química Orgánica e Inorgánica/IUQOEM. Universidad de Oviedo

C/Julian Clavería, 8, 33071 Oviedo (Spain)

E-mail: mara@uniovi.es

Supporting information for this article is given via a link at the end of the document. attractive alternative for the stabilization of this type of molecules, then avoiding the presence of additional Lewis bases attached at the Si atom. Thus, Filippou and co-workers reported in 2014 the synthesis of what can be regarded as a metallated silanone, $\left[\mathrm{CrCp}^{*}(\mathrm{CO})_{3}\{\mathrm{Si}(=\mathrm{O}) \text { SIdipp }\}\right]^{+}\left(\mathrm{Cp}^{*}=\eta^{5}-\mathrm{C}_{5} \mathrm{Me}_{5}\right.$; Sldipp $=$ 1,3-bis (2,6-diisopropylphenyl)imidazolidin-2-ylidene) $\quad(\mathbf{C}$ in Figure 1), ${ }^{[9]}$ a remarkable compound featuring a $\mathrm{Si}=\mathrm{O}$ bond in which the three-coordinate $\mathrm{Si}$ atom is also bonded to $\mathrm{Cr}$ and to a NHC group. Interestingly, DFT calculations supported the view of this compound as a metallasilanone, as the alternative view as a NHC-stabilized silicon monoxide complex seems to have relatively small contribution to the ground state configuration. Very recently (2016) Tobita and co-workers reported the synthesis of the anionic complexes $\left[\mathrm{WCp}^{R}(\mathrm{CO})_{2}\left\{\eta^{2}-\mathrm{OSiH}(\mathrm{Tsi})\right\}\right]^{-}$ $\left(\mathrm{Cp}^{R}=\eta^{5}-\mathrm{C}_{5} \mathrm{Me}_{4} \mathrm{R}, \mathrm{R}=\mathrm{Me}\right.$, Et; Tsi $\left.=\mathrm{C}\left(\mathrm{SiMe}_{3}\right)_{3}\right)$, the first compounds with a $\eta^{2}$-coordinated silaaldehyde ligand (D in Figure 1), which were prepared by oxidation of the corresponding silylene $\left(\mathrm{M}=\mathrm{SiR}_{2}\right)$ complexes using pyridine $\mathrm{N}$ oxide. ${ }^{[10]}$ In spite of these recent advancements, silanone and related complexes remain exceedingly rare, ${ }^{[11]}$ and hence very little information is available about the potential coordination modes and electronic properties of silanones as ligands.<smiles>[R][Sb]([R])(C)O[CH]CCO</smiles><smiles>[R][SiH](C)OC</smiles>

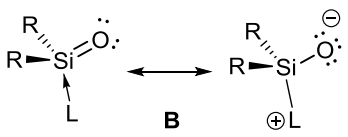
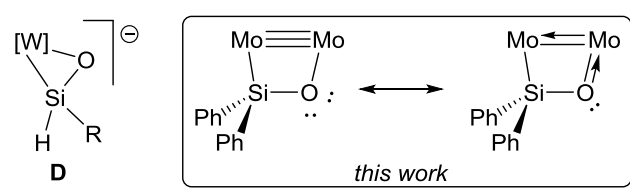

Figure 1. Resonance forms of silanones (A). Resonance forms of base-stabilized silanones (B). Metallated silanone reported by Filippou and co-workers (C). $\eta^{2}$-coordinated silaaldehyde reported by Tobita and co-workers (D).

As part of our ongoing interest in unsaturated dinuclear complexes, ${ }^{[12]}$ herein we report the preparation and structural characterization of the 30-electron dimolybdenum complex $\left[\mathrm{Mo}_{2} \mathrm{Cp}_{2}(\mu-\mathrm{CPh})\left(\mu-\mathrm{PCy}_{2}\right)\left(\mu-\kappa^{1}: \kappa^{1}-\mathrm{OSiPh}_{2}\right)\right](3)$, the first transition metal complex bearing a silanone ligand (diphenylsilanone has only been identified in cryogenic matrixes ${ }^{[13]}$ ) and also the first dinuclear example of this family of complexes. Surprisingly, compound $\mathbf{3}$ is easily accessible by a two-step procedure involving the selective oxidation with molecular $\mathrm{O}_{2}$ of an intermediate silylene complex $\left[\mathrm{Mo}_{2} \mathrm{Cp}_{2}(\mu-\mathrm{CPh})\left(\mu-\mathrm{PCy}_{2}\right)(\mu-\right.$ $\left.\mathrm{SiPh}_{2}\right)$ ] (2), which in turn is generated in situ from the readily available 30 -electron benzylidyne-bridged complex $\left[\mathrm{Mo}_{2} \mathrm{Cp}_{2}(\mu-\right.$ $\left.\mathrm{CPh})\left(\mu-\mathrm{PC} \mathrm{y}_{2}\right)(\mu-\mathrm{CO})\right](\mathbf{1}) \cdot{ }^{[14]}$ As shown below, our results reveal for the first time the potential of silanones as bridging ligands in polynuclear transition metal complexes, as well as its 
unprecedented ability to fine-tune their electron donation properties to further stabilize electronically unsaturated complexes by using oxygen lone pairs for $\pi$-bonding with the metal atoms.

The silylene-bridged compound 2 can be conveniently prepared in high yield (ca. $70 \%$ ) by reaction of the 30-electron carbyne complex $\left[\mathrm{Mo}_{2} \mathrm{Cp}_{2}(\mu-\mathrm{CPh})(\mu-\mathrm{PCy})(\mu-\mathrm{CO})\right]$ (1) with excess $\mathrm{Ph}_{2} \mathrm{SiH}_{2}$ under visible-UV irradiation (Scheme 1). No intermediates could be detected in the course of this necessarily multi-step reaction, overall involving full dehydrogenation of the silane molecule and release of carbon monoxide. In any case, the outcome of this reaction is not fully unexpected since a limited number of related reactions with silanes, also involving release of $\mathrm{H}_{2}$ and $\mathrm{CO}$, have been reported to yield bridging silylene derivatives, such as the complexes $\left[\mathrm{Pt}_{2}\left(\mu-\mathrm{SiMe}_{2}\right)(\mu-\right.$ $\left.\mathrm{dppm})_{2}(\mathrm{CO})_{2}\right]^{[15]}$ or $\left[\mathrm{W}_{2}\left(\mu-\mathrm{SiPh}_{2}\right)(\mathrm{CO})_{10}\right]^{[16]} \quad$ Unfortunately, compound 2 is quite air-sensitive (vide infra) and this prevented us from obtaining $X$-ray quality crystals; yet the available spectroscopic data in solution, ${ }^{[17]}$ and its similarity with those of the parent compound 1, give full support to the structure proposed. Replacement of the $\mathrm{CO}$ in $\mathbf{1}$ with an isoelectronic diphenylsilylene $\left(\mathrm{SiPh}_{2}\right)$ group is firmly supported by the presence of the corresponding aromatic resonances in the ${ }^{1} \mathrm{H}$ and ${ }^{13} \mathrm{C}$ NMR spectra, along with the absence of $\mathrm{C}-\mathrm{O}$ stretching bands in the IR spectra. Accordingly, the ${ }^{29} \mathrm{Si}\left\{{ }^{1} \mathrm{H}\right\}$ NMR spectrum displays a single resonance at $241 \mathrm{ppm}$ showing a modest coupling to phosphorus $\left(J_{\mathrm{Sip}}=17 \mathrm{~Hz}\right)$, and being not far away from the chemical shift found for the above mentioned $\mathrm{SiPh}_{2-}$ bridged ditungsten compound $\left(\delta_{\mathrm{Si}}=211 \mathrm{ppm}\right)$. Full dehydrogenation of the silane molecule is also indicated by the lack of $\mathrm{Si}-\mathrm{H}$ resonances in the ${ }^{1} \mathrm{H}$ spectra, while the retention of a bridging phenylcarbyne ligand is firmly supported by the diagnostic appearance of a strongly deshielded resonance in the ${ }^{13} \mathrm{C}$ NMR spectrum $\left(\delta_{\mathrm{C}}=395 \mathrm{ppm}\right)$. All of this renders 2 as an unsaturated 30-electron compound, for which a metal-metal triple bond should be formulated according to the 18-electron rule, a situation which is in agreement with the highly deshielded ${ }^{31} \mathrm{P}$ resonance of this compound $(\delta \mathrm{p}=260.5 \mathrm{ppm}) .{ }^{[18]}$

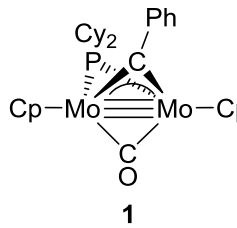
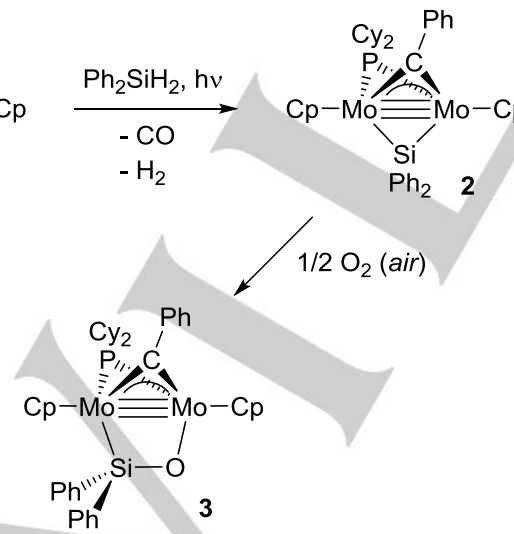

Scheme 1. Synthesis of new complexes. $\left(\mathrm{Cp}=\eta^{5}-\mathrm{C}_{5} \mathrm{H}_{5}\right)$.

As mentioned above, the silylene complex 2 is remarkably air-sensitive; in fact, exposure of a $\mathrm{CH}_{2} \mathrm{Cl}_{2}$ solution of this compound to air for just 30 seconds and further stirring (10 min) under a nitrogen atmosphere leads to a progressive color change from yellow to green (Scheme 1). ${ }^{31} \mathrm{P}$ NMR monitoring of the reaction confirms the quantitative formation of a new organometallic species characterized by a highly deshielded ${ }^{31} \mathrm{P}$ resonance $(\delta \mathrm{p}=255 \mathrm{ppm})$, again indicative of the unsaturated nature of the product formed. ${ }^{[18]}$ This new compound can be conveniently isolated and purified by column chromatography and has been fully characterized by NMR spectroscopy and Xray diffraction as the diphenylsilanone-bridged complex $\left[\mathrm{Mo}_{2} \mathrm{Cp}_{2}(\mu-\mathrm{CPh})(\mu-\mathrm{PCy})\left(\mu-\kappa^{1}: \kappa^{1}-\mathrm{OSiPh}_{2}\right)\right]$ (3). In order to rule out the participation of water as oxygen source in this transformation, a solution of $\mathbf{2}$ was stirred under a rigorous nitrogen atmosphere with a drop of degassed $\mathrm{H}_{2} \mathrm{O}$, which caused no transformation of the starting compound even after 10 minutes. It must be concluded, then, that the source of oxygen in this reaction is the elemental $\mathrm{O}_{2}$ present in air. There are several points of interest in this chemistry. First, in spite of the great number of silylene complexes reported so far, this reaction represents the third example of formation of a stable silanone-like complex by oxidation of a silylene group, ${ }^{[10,11]}$ the first one occurring at a bridging silylene group and also the first one in which molecular $\mathrm{O}_{2}$ acts as a mild source of oxygen atoms. Secondly, compound $\mathbf{3}$ is the first polynuclear compound containing a silanone ligand, hence revealing for the first time the potential of these molecules to act effectively as bridging ligands in multinuclear complexes.

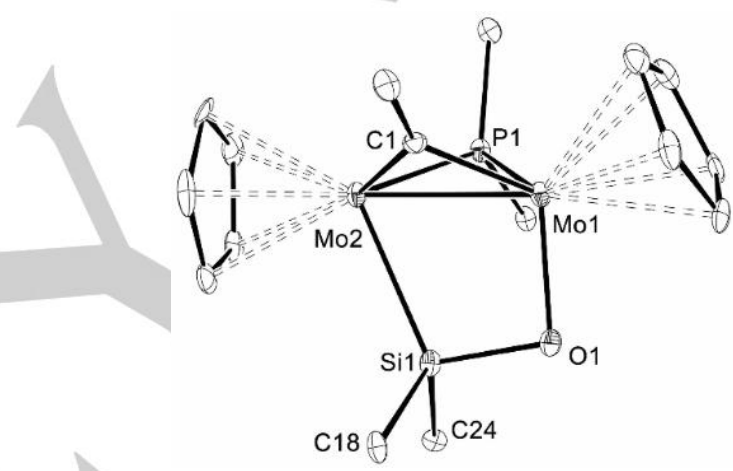

Figure 2. ORTEP diagram ( $30 \%$ probability) of compound $\mathbf{3}$ with $\mathrm{H}$ atoms, $\mathrm{Cy}$ and $\mathrm{Ph}$ groups (except $\mathrm{C} 1$ atoms) and solvent molecule (hexane) omitted for clarity. Selected bond lengths $(\AA)$ and angles $\left({ }^{\circ}\right)$ : Mo1-Mo2 2.571(1), Mo1-C1 1.998(5), Mo2-C1 1.954(5), Mo1-O1 1.964(4), Mo2-Si1 2.512(2), Mo1-Si1 2.716(2), Si1-O1 1.670(4), Mo1-P1 2.398(2), Mo2-P1 2.344(2), Mo1-C1-Mo2 81.2(2), Mo1-P1-Mo2 65.6(1), Mo1-Si1-Mo2 58.8(1), Mo2-Si1-O1 104.6(2), Mo2-Si1-O1 104.7(1), Mo2-Si1-C18 115.3(2), Mo2-Si1-C24 118.2(2), C18-Si1-C24 108.1(2), C18-Si1-O1 102.7(2), C24-Si1-O1 106.3(2).

The solid-state structure of 3 (Figure 2) ${ }^{[19]}$ displays two MoCp fragments connected by three bridging ligands: dicyclohexylphosphide, benzylidyne and a diphenylsilanone molecule bound in a $\kappa^{1}: \kappa^{1}$-coordination mode. The Mo2-Si bond length $(2.512(2) \AA)$ is consistent with a single bond formulation, falling within the range typically observed for $\mathrm{Mo}-\mathrm{SiX}_{3}$ bonds $(2.43-2.68 \AA),{ }^{[20]}$ and being only slightly longer than that measured for Tobita's $\eta^{2}$-silaaldehyde complex (W-Si $=2.47$ $\AA) .{ }^{[10]}$ A similar lengthening is observed for the Si-O bond $(1.670(4) \AA)$, ca. $0.04 \AA$ longer than the same bond in the silaaldehyde compound and nearly $0.1 \AA$ longer than the reference values measured for base-stabilized silanones (1.54$1.58 \AA),{ }^{[7,8]}$ therefore being compatible with a single bond formulation. In contrast, the Mo1-O bond distance in 3 (1.964(4) $\AA)$ unexpectedly is much shorter than that one in the silaaldehyde complex $(\mathrm{W}-\mathrm{O}=2.24 \AA)^{[10]}$ and also significantly shorter than the length expected for a dative Mo $\leftarrow \mathrm{O}$ bond, such as those found for different $\kappa^{1}$-ketone compounds ${ }^{[21]}$ or the 
DMAP-stabilized silanone complex $\left[\mathrm{WCp}^{*}(\mathrm{CO})_{2}\left(\mathrm{SiMe}_{3}\right)\left(\kappa^{1}-\right.\right.$ $\left.\mathrm{O}=\mathrm{Si}\left(\mathrm{DMAP}_{\mathrm{M}} \mathrm{Mes}_{2}\right)\right] \quad(2.17 \quad \AA$ ) $($ DMAP $=4$ dimethylaminopyridine). ${ }^{[1]}$ In fact, this value approaches the $\mathrm{M}-\mathrm{O}$ bond lengths found for the dimolybdenum compound $\left[\mathrm{Mo}_{2} \mathrm{ReCp}_{2} \mathrm{Cp}{ }^{\prime}(\mu-\mathrm{N})(\mu-\mathrm{O})\left(\mu-\mathrm{PPh}_{2}\right)(\mathrm{O})(\mathrm{CO})_{2}\right]$, with a four-electron donor oxo ligand bridging the Mo atoms (av. Mo-O $1.97 \AA){ }^{[22]}$ or that in the $\eta^{2}$-acetone complex $\left[\mathrm{W}(\mathrm{acac})_{2}(\mathrm{CO})\left(\eta^{2}-\mathrm{O}=\mathrm{CMe}_{2}\right)\right]$ $(1.93 \AA)^{[23]}$ for which a strong four-electron coordination of the acetone molecule was supported by a theoretical study. It must be then concluded that the short Mo1-O distance in $\mathbf{3}$ is indicative of the presence of substantial multiplicity in that bond, a view also supported by DFT calculations to be discussed later on. Altogether, this would make the silanone ligand to behave as a donor of more than two electrons to the dimetal unit, which in turn is consistent with the substantial lengthening ( $c a .0 .1 \AA$ ) of the Mo-Mo bond in 3 (2.571(1) $\AA$ ), when compared with the parent carbonyl complex $1(2.465 \AA) \cdot{ }^{[14]}$ Although bonding in the central $\mathrm{Mo}_{2} \mathrm{SiO}$ skeleton of 3 might be described in principle through several canonical forms (Figure 3), the above structural parameters suggest that a combination of the canonical forms II and III would best describe the actual bonding within the $\mathrm{Mo}_{2} \mathrm{SiO}$ ring, which then would approach the extreme description of a dimetallacyclosiloxane, a view also supported by DFT calculations. Finally, we note that all available NMR data for 3 indicate that the solid state structure is essentially retained in solution. Of particular relevance is the quite shielded ${ }^{29} \mathrm{Si}$ resonance of $3\left(\delta_{\mathrm{Si}}=-1.1 \mathrm{ppm}\right)$ when compared with its parent silylene complex 2 ; this shielding effect upon insertion of oxygen into the M-Si bond of a silylene group is similar to that found by Tobita and co-workers for their silaaldehyde complexes $\left(\delta_{\mathrm{si}} \approx\right.$ $-20 \mathrm{ppm}){ }^{[10]}$ The asymmetry introduced by the $\kappa^{1}: \kappa^{1}-$ coordination of the silanone ligand renders inequivalent $\mathrm{Cp}$ and Cy groups, while retaining highly deshielded ${ }^{13} \mathrm{C}$ and ${ }^{31} \mathrm{P}$ resonances for the bridging benzylidyne and phosphide ligands, respectively.

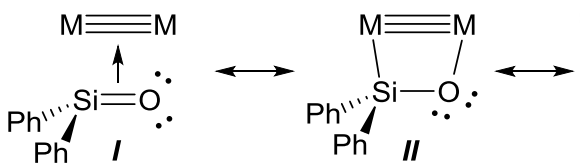<smiles>[M]O[Si](c1ccccc1)(c1cccnc1)c1cccnc1</smiles>

Figure 3. Canonical forms describing the metal-ligand and metal-metal bonding in compound 3 .

In order to shed additional light into the electronic structure of the silanone complex 3 , we carried out density functional theory (DFT) calculations on the isolated molecule. ${ }^{[24]}$ First we note that the B3LYP-optimized structure is very similar to the one found in the crystal (Table S2), in particular retaining a short Mo-O (1.98 A) interaction and essentially single bond distances for the Si-O $(1.70 \AA)$ and Mo-Si bonds $(2.55 \AA)$. As for the molecular orbitals (Table S3), an analogy with the parent compound 1 can be clearly traced, with the metal-metal bonding in 3 following from a $\sigma^{2} \delta^{2} \delta^{2}$ configuration, with one of the two $\delta$ components being somewhat mixed with the $\pi$ component of the bonding with the carbyne group. Indeed, the HOMO of the molecule corresponds to one of the $\delta_{\mathrm{MM}}$ components, while orbital $\mathrm{HOMO}-2$ corresponds to a tricentric $\mathrm{Mo}_{2} \mathrm{C} \delta / \pi$-type interaction. However, the orbital corresponding to the $\sigma_{\mathrm{MM}}$ bond, which typically appears at energies lower than those of the $\delta$ bonding orbitals, has now raised in energy and split into orbitals HOMO-1 and HOMO-3 (Figure 4) due to mixing with the Mo-Si $\sigma$-type bond. The $\pi$-component of the $\mathrm{Si}-\mathrm{O}$ bond, expected for a silanone molecule, has disappeared completely upon coordination as anticipated by the long $\mathrm{Si}-\mathrm{O}$ distance found in the solid-state structure. Quite interestingly, two orbitals display significant $\mathrm{M}-\mathrm{O}$ bonding character, with the orbital HOMO-31 representing the corresponding $\sigma$-type interaction (Table S3), while the HOMO-22 (Figure 4) denotes the presence of a nonnegligible $\pi(\mathrm{Mo}-\mathrm{O})$ interaction which supports the relevant contribution of canonical form III (Figure 3) to represent the bonding situation within the central $\mathrm{Mo}_{2} \mathrm{SiO}$ ring of the molecule. Such a $\pi$-component in the $\mathrm{M}-\mathrm{O}$ interaction is unprecedented, and it is likely favoured by the particularly high electronic unsaturation of the dimetal centre in $\mathbf{3}$. It is worth noting that this situation is opposite to the one found for the above mentioned silaaldehyde complex, comprising an anionic (electron rich) metal centre, for which repulsive interactions between the $\mathrm{W}$ and $O$ atoms were identified across several orbitals, ${ }^{[10]}$ this apparently being the origin of the long $\mathrm{W}-\mathrm{O}$ length observed in that case. Therefore, our results prove the ability of the silanone ligand to fine-tune its electron releasing properties to better accommodate the special electronic requirements of the metal centre, a feature which has no precedents for this family of ligands, but has been observed in a limited number of cases for ketones. ${ }^{[23]}$

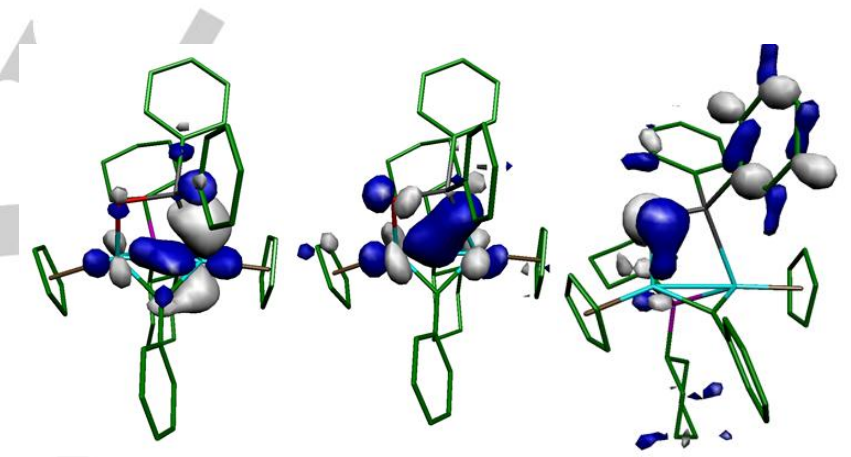

Figure 4. Relevant Kohn-Sham orbitals for 3 (HOMO-1, HOMO 3, HOMO-22 from left to right).

The picture of the bonding in $\mathbf{3}$ obtained from the analysis of the molecular orbitals, in which the $\mathrm{Si}=\mathrm{O}$ bond of the silanone has completely disappeared, is essentially sustained by other indicators such as Mayer bond indices (MBI), Natural Population Analysis (NPA) derived charges or even by the topological analysis of the electron density as managed by the Atoms-inMolecules (AIM) ${ }^{[25]}$ theory (see Supporting Information). This is most clearly evidenced by the strong decrease of both the MBI (0.854) and electron density at the bond critical point $(0.797 \mathrm{e} \AA$ $\left.{ }^{3}\right)$ in the Si-O bond of 3 when compared to the corresponding values calculated for the free diphenylsilanone molecule using the same methodology (1.839 and $1.147 \mathrm{e}^{-3}$, respectively). In agreement with this, the $\mathrm{Si}-\mathrm{O}$ bond also shows a strong polarization as evidenced by the large magnitude of the calculated NPA charges (Si: 1.77, O: -0.96). Finally, the relatively high electron density at the Mo-O bond critical point $\left(0.832 \mathrm{e}^{-3}\right)$ gives further support to the presence of a significant $\pi$-bonding interaction between these two atoms as also indicated by the orbital analysis, although we must note that data on related compounds for comparative purposes are scarce. ${ }^{[22]}$

In summary, we have reported the synthesis of $\left[\mathrm{Mo}_{2} \mathrm{Cp}_{2}(\mu-\right.$ $\left.\mathrm{CPh})\left(\mu-\mathrm{PCy}_{2}\right)\left(\mu-\kappa^{1}: \kappa^{1}-\mathrm{OSiPh}_{2}\right)\right]$ (3), the first transition metal complex having a silanone ligand, which is also the first polynuclear complex having a bridging ligand of this type. Given 
the rather limited previous knowledge of these molecules when bound to metal atoms, our results add new valuable information about the versatility of the coordination modes affordable by these ligands and also about their ability to fine-tune their electron-releasing properties to accommodate the particular demands of the metal centre. In compound $\mathbf{3}$, bonding within the central $\mathrm{Mo}_{2} \mathrm{SiO}$ ring approaches the extreme description of a dimetallacyclosiloxane, with the bridging $\mathrm{OSiPh}_{2}$ group donating more than two electrons to the dimetal unit thanks to the involvement of an O-lone electron pair in $\pi$-bonding with the metal centre. An initial exploration of the reactivity of the silanone complex $\mathbf{3}$ is currently under way in our laboratory.

\section{Acknowledgements}

We thank the DGI of Spain (Project CTQ2012-33187) for supporting this work. We also thank the Universidad de Santiago de Compostela (Unidad de Rayos X) for collection of diffraction data and the CMC of Universidad de Oviedo for access to computing facilities.

Keywords: Silanones $・$ Molybdenum $•$ Silylene $・$ Metallacycles $•$ Silicon • Metal-Metal Bonds

[1] F. S. Kipping, L. L. Lloyd, J. Chem. Soc. 1901, 79, 449-459.

[2] a) For a recent example of persistent silanone at low temperature see: S. Ishida, T. Abe, F. Hirakawa, T. Kosai, K. Sato, M. Kira, T. Iwamoto, Chem. Eur. J. 2015, 21, 15100-15103. b) For a recent example of matrix isolation see: M. M. Linden, H. P. Reisenauer, D. Gerbig, M. Karni, A. Schäfer, T. Müller, Y. Apeloig, P. R. Schreiner, Angew. Chem. Int. Ed. 2015, 54, 12404-12409. c) For other examples of matrix isolation see: G. Maier, A. Meudt, J. Jung, H. Pacl, in The Chemistry of Organic Silicon Compounds, Vol. 2 (Eds.: Z. Rappoport, Y. Apeloig), Wiley, Chichester, 1998, pp. 1143-1185.

[3] R. G. Jones, W. Ando, J. Chojnowski, Silicon-Containing Polymers: The Science and Technology of Their Synthesis, Springer Science \& Business Media, 2000

[4] N. Tokitoh, R. Okazaki, in The Chemistry of Organic Silicon Compounds, Vol. 2 (Eds.: Z. Rappoport, Y. Apeloig), Wiley, Chichester 1998, pp. $1063-1103$.

[5] a) T. Kudo, S. Nagase, J. Am. Chem. Soc. 1985, 107, 2589-2595; b) M. Kimura, S. Nagase, Chem. Lett. 2001, 1098-1099.

[6] R. Okazaki, N. Tokitoh, Acc. Chem. Res. 2000, 33, 625-630.

[7] S. Yao, M. Brym, C. van Wüllen, M. Driess, Angew. Chem. Int. Ed. 2007, 46, 4159-4162.

[8] a) Y. Xiong, S. Yao, M. Driess, J. Am. Chem. Soc. 2009, 131, 7562 7563; b) Y. Xiong, S. Yao, R. Müller, M. Kaupp, M. Driess, Nat. Chem. 2010, 2, 577-580; c) Y. Xiong, S. Yao, R. Müller, M. Kaupp, M. Driess, J. Am. Chem. Soc. 2010, 132, 6912-6913; d) R. S. Ghadwal, R Azhakar, H. W. Roesky, K. Pröpper, B. Dittrich, S. Klein, G. Frenking, J. Am. Chem. Soc. 2011, 133, 17552-17555; e) R. S. Ghadwal, R. Azhakar, H. W. Roesky, K. Propper, B. Dittrich, C. Goedecke, G. Frenking, Chem. Commun. 2012, 48, 8186-8188; f) R. Rodriguez, D. Gau, T. Troadec, N. Saffon-Merceron, V. Branchadell, A. Baceiredo, T. Kato, Angew. Chem. Int. Ed. 2013, 52, 8980-8983; g) R. Rodriguez, T. Troadec, D. Gau, N. Saffon-Merceron, D. Hashizume, K. Miqueu, J.-M. Sotiropoulos, A. Baceiredo, T. Kato, Angew. Chem. Int. Ed. 2013, 52, 4426-4430; h) Y. Xiong, S. Yao, M. Driess, Angew. Chem. Int. Ed. 2013, 52, 4302-4311.

[9] A. C. Filippou, B. Baars, O. Chernov, Y. N. Lebedev, G. Schnakenburg, Angew. Chem. Int. Ed. 2014, 53, 565-570.

[10] T. Fukuda, H. Hashimoto, S. Sakaki, H. Tobita, Angew. Chem. Int. Ed. 2016, 55, 188-192.

[11] A DMAP (DMAP = 4-dimethylaminopyridine) stabilized compound has also been recently reported by the group of Ueno and co-workers: $T$.
Muraoka, K. Abe, Y. Haga, T. Nakamura, K. Ueno, J. Am. Chem. Soc. 2011, 133, 15365-15367.

[12] D. García-Vivó, A. Ramos, M. A. Ruiz, Coord. Chem. Rev. 2013, 257, 2143-2191.

[13] V. N. Khabashesku, Z. A. Kerzina, K. N. Kudin, O. M. Nefedov, J. Organomet. Chem. 1998, 566, 45-59.

[14] M. A. Alvarez, M. E. García, M. E. Martínez, S. Menéndez, M. A. Ruiz, Organometallics 2010, 29, 710-713.

[15] K. A. Brittingham, T. N. Gallaher, S. Schreiner, Organometallics 1995, 14, 1070-1072.

[16] A. Gądek, A. Kochel, T. Szymańska-Buzar, Organometallics 2003, 22, 4869-4872.

[17] The Supporting Information (SI) contains the synthesis, analytical and spectroscopic data of the new complexes and details of the DFT calculations on these compounds.

[18] M. E. García, V. Riera, M. A. Ruiz, M. T. Rueda, D. Sáez, Organometallics 2002, 21, 5515-5525.

[19] CCDC 1446406 contain the crystallographic data for compound 3 These data can be obtained free of charge from The Cambridge Crystallographic Data Centre via www.ccdc.cam.ac.uk/data request/cif.

[20] Bond lenghts range was taken from the Cambridge Structura Database, CSD version 5.36 (Update 3, May 2015)

[21] a) K. M. Nicholas, M. A. Khan, Inorg. Chem. 1987, 26, 1633-1636; b) G. Wahl, D. Kleinhenz, A. Schorm, J. Sundermeyer, R. Stowasser, C Rummey, G. Bringmann, C. Fickert, W. Kiefer, Chem. Eur. J. 1999, 5, 3237-3251; c) H. Seino, D. Nonokawa, G. Nakamura, Y. Mizobe, M. Hidai, Organometallics 2000, 19, 2002-2011; d) S. Namorado, M. A Antunes, L. F. Veiros, J. R. Ascenso, M. T. Duarte, A. M. Martins, Organometallics 2008, 27, 4589-4599; e) V. Vrdoljak, B. Prugovecki, D. Matkovic-Calogovic, J. Pisk, CrystEngComm 2011, 13, 4382-4390; f) B Oelkers, A. Venker, J. Sundermeyer, Inorg. Chem. 2012, 51, 46364643

[22] M. E. García, D. García-Vivó, S. Melón, M. A. Ruiz, C. Graiff, A Tiripicchio, Inorg. Chem. 2009, 48, 9282-9293.

[23] A. B. Jackson, C. K. Schauer, P. S. White, J. L. Templeton, J. Am. Chem. Soc. 2007, 129, 10628-10629.

[24] Density Functional Theory (DFT) calculations were performed with the GAUSSIAN03 program package using the hybrid method B3LYP together with standard $6-31 G^{*}$ basis on all atoms except Mo, for which a valence double- $\xi$ quality basis set and LANL2DZ effective core potentials were used. See the SI for further details.

[25] R. F. W. Bader, Atoms in Molecules: A Quantum Theory, Oxford University Press, Oxford, 1990. 


\section{COMMUNICATION}

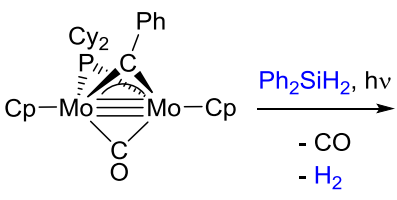

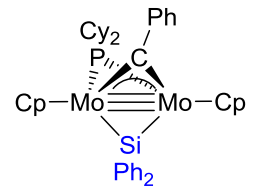

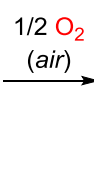

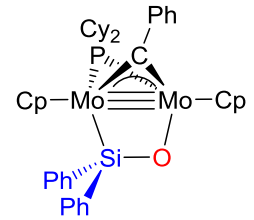

An unsaturated dimolybdenum complex with a bridging diphenylsilanone $\left(\mathrm{OSiPh}_{2}\right)$ ligand has been prepared by selective oxidation with elemental oxygen of an intermediate silylene complex. X-ray data and DFT calculations indicate that the central $\mathrm{Mo}_{2} \mathrm{SiO}$ ring in this compound approaches the extreme description of dimetallacyclosiloxane ring, with an O-lone electron pair also involved in bonding with the dimetal unit.
M. Angeles Alvarez, M. Esther García, Daniel García-Vivó, * Sonia Menéndez and Miguel A. Ruiz*

Page No. - Page No.

Synthesis and DFT Study of a Diphenylsilanone-Bridged Dimolybdenum Complex 